\title{
Deteriorating resources for undergraduate medical education in Peradeniya Medical School
}

\author{
HBPW Wickramanayake, HLPS Dharmapala, DMPKD Basnayake, MMED Dissanayake, \\ KAPP Kanankearachchi, CDA Goonasekera \\ Department of Anaesthesiology, Faculty of Medicine, University of Peradeniya, Sri Lanka \\ Correspondence: Prof.C.D.A.Goonasekera (cgoonase@slt.lk)
}

\begin{abstract}
Objective: To study the resources available for final year undergraduate clinical medical education in the professorial units.

Design: The number of academic staff and the number of hospital beds available in the clinical departments were studied in relation to the number of students admitted annually from 1981-2004. Annual recurrent funding (adjusted according to the Colombo Consumer Price Index) made available per student from 1994-2004 was also studied.
\end{abstract}

Setting: Faculty of Medicine, University of Peradeniya, Sri Lanka.

Results: There was a steady increase in the student: staff ratio and a reduction in the hospital beds: student ratio in all professorial units. The student: staff ratio increased from 15.2 to $48(215.7 \%), 19$ to $48(152.6 \%), 9.5$ to 21.3 $(124.2 \%)$ and 12.7 to $21.3(66.4 \%)$ respectively in the departments of Pediatrics, Obstetrics \& Gynecology, Surgery and Medicine while the hospital beds per student ratio declined from 2.2 to 1.6 (26.6\%), 5.6 to 2.7 (51.5\%), 4.7 to $1.9(58.7 \%)$ and 5.2 to $2.3(56.3 \%)$ respectively from 1981-2004. The recurrent funds utilized per student also reduced from Rs. 11,542/- to Rs. 9,352/-(18.9\%), Rs. 8,149/- to Rs. 5,477/- (32.7\%), Rs. 13,114/- to Rs. 8,972/-(31.5\%) and Rs. 18,109/- to Rs. 12,142/- (32.9\%) from 1994-2004 (Prices adjusted according to the Colombo Consumers' Price index) in respective departments.

Conclusion: There has been a gradual deterioration in funding, academic staffing and hospital beds available for undergraduate medical education in all (professorial) clinical units over the last 2 decades.

\section{Index Words: Resources, Facilities, Undergraduate, Medical Education}

\section{Background}

In the early stages of university education in Sri Lanka, the number of students entering the universities for medical education was small and the national government funding alone was considered adequate for the provision of resources, free of charge, depicted by the parliamentary act. During the past two decades, the demand for medical education rose globally resulting in the establishment of new medical schools and an increased student intake for the existing medical schools. Medical Education of quality demands a great deal of human and financial resources. Foundation of medical schools driven by political influences and personal ambitions has unfortunately resulted in the establishment of medical schools with lesser resources (1). With this global trend, there was a comparative increase in the number of Sri Lankan medical schools too with almost a quadrupled number of medical students entering over the last 2 decades $(2,3)$. Furthermore, the costs of medical education also rose over time, especially due to the increasing undergraduate debt and consumer debt $(4,5)$. In addition to the above trends, the demand for reorganization of undergraduate medical education through curricular reforms also resulted in a need for more innovative and resource intense curricula with a need for enhanced financial and institutional 
resources in parallel (6). Despite the wide interest for review, revision and upgrade of undergraduate medical education in Sri Lanka, there is an impression among the public and academic staff that the resources made available for the same may have lessened.

\section{Aim}

To assess the academic staffing, clinical learning environment in hospital and the finances made available for undergraduate final year clinical medical education at the Faculty of Medicine, Peradeniya during the last two decades.

\section{Methodology}

We collected the relevant documented data from the dean's office, the clinical departments and the accounts branch records of the Faculty of Medicine, Peradeniya and the inventories of the Teaching Hospital, Peradeniya with the consent from all Heads of Clinical Departments and the Director of the Hospital. The numbers of medical students, full time academic staff and their profiles and the hospital beds available for clinical teaching were recorded in all professorial units of the Faculty of Medicine, Peradeniya from 1981 to 2004 . The annual recurrent expenditure (this encompasses all departmental expenditure excluding capital funding used for buildings and equipment) made available for each department from 1994 to 2004 was also studied and was adjusted according to Colombo Consumer Price Index (to enable comparisons whilst accounting for value depreciations) published in the Central Bank Annual Reports of 1998 \& 2004 relevant for the study period (7). Data were recorded in a computerized data entry sheet and graphical analyses were done using Microsoft Excel software.
The evaluated indices were;

(a) Student: staff ratio and the staff profiles,

(b) The number of hospital beds available per student and

(c) The recurrent funds utilized per student per year in each department.

(d) Student performance in the final MBBS examination

\section{Results}

During the 23 year study period, the number of undergraduates entering the professorial departments has increased from 76 in 1981 to 192 in 2004 (Table 1), whilst the numbers of full time academic staff positions show no parallel increase in the professorial clinical departments (Figure 1). The full time academic staff positions have increased only in the Departments of Medicine and Surgery i.e. from 6 to 9 and 8 to 9 respectively whilst there was no change in the Department of Gynaecology \& Obstetrics. One position was reduced in the Department of Paediatrics from five to four (Figure 1). As a result, the student: staff ratio increased from 15.2 to $48(215.7 \%), 19$ to 48 (152.6\%), 9.5 to $21.3(124.2 \%)$ and 12.6 to 21.3 $(66.4 \%)$ respectively in the departments of Pediatrics, Obstetrics \& Gynecology, Surgery and Medicine (Figure 2). The number of hospital beds that were available per student in all the Professorial units of the Teaching Hospital, Peradeniya from 1981 to 2004 showed a reduction as shown in Table 1 (Figure 3). The adjusted values for annual expenditure utilized per student per annum from 1994 to 2004 also declined, on average by $30 \%$ in all departments from 1994 to 2004 (Table 2, Figure 4). However, there was no change observed in the student performance in the final MBBS examination during the study period (Figure 5).

Table 1: Hospital beds: student ratio from 1981 to 2004

\begin{tabular}{llllllll}
\hline Department & \multicolumn{2}{l}{$\begin{array}{l}\text { Number of } \\
\text { students }\end{array}$} & \multicolumn{2}{l}{$\begin{array}{l}\text { Number of } \\
\text { hospital beds }\end{array}$} & $\begin{array}{l}\text { Hospital beds } \\
\text { per student }\end{array}$ & \% Change \\
\hline & $\mathbf{1 9 8 1}$ & $\mathbf{2 0 0 4}$ & $\mathbf{1 9 8 1}$ & $\mathbf{2 0 0 4}$ & $\mathbf{1 9 8 1}$ & $\mathbf{2 0 0 4}$ & $\mathbf{1 9 8 1 ~ t o ~ 2 0 0 4}$ \\
Medicine & 76 & 192 & 98 & 108 & 5.15 & 2.25 & $(-56.31 \%)$ \\
Surgery & 76 & 192 & 89 & 93 & 4.68 & 1.93 & $(-58.76 \%)$ \\
Paediatrics & 76 & 192 & 42 & 78 & 2.21 & 1.62 & $(-26.69 \%)$ \\
Obstetrics \& Gynaecology & 76 & 192 & 107 & 131 & 5.63 & 2.73 & $(-51.52 \%)$ \\
\hline
\end{tabular}



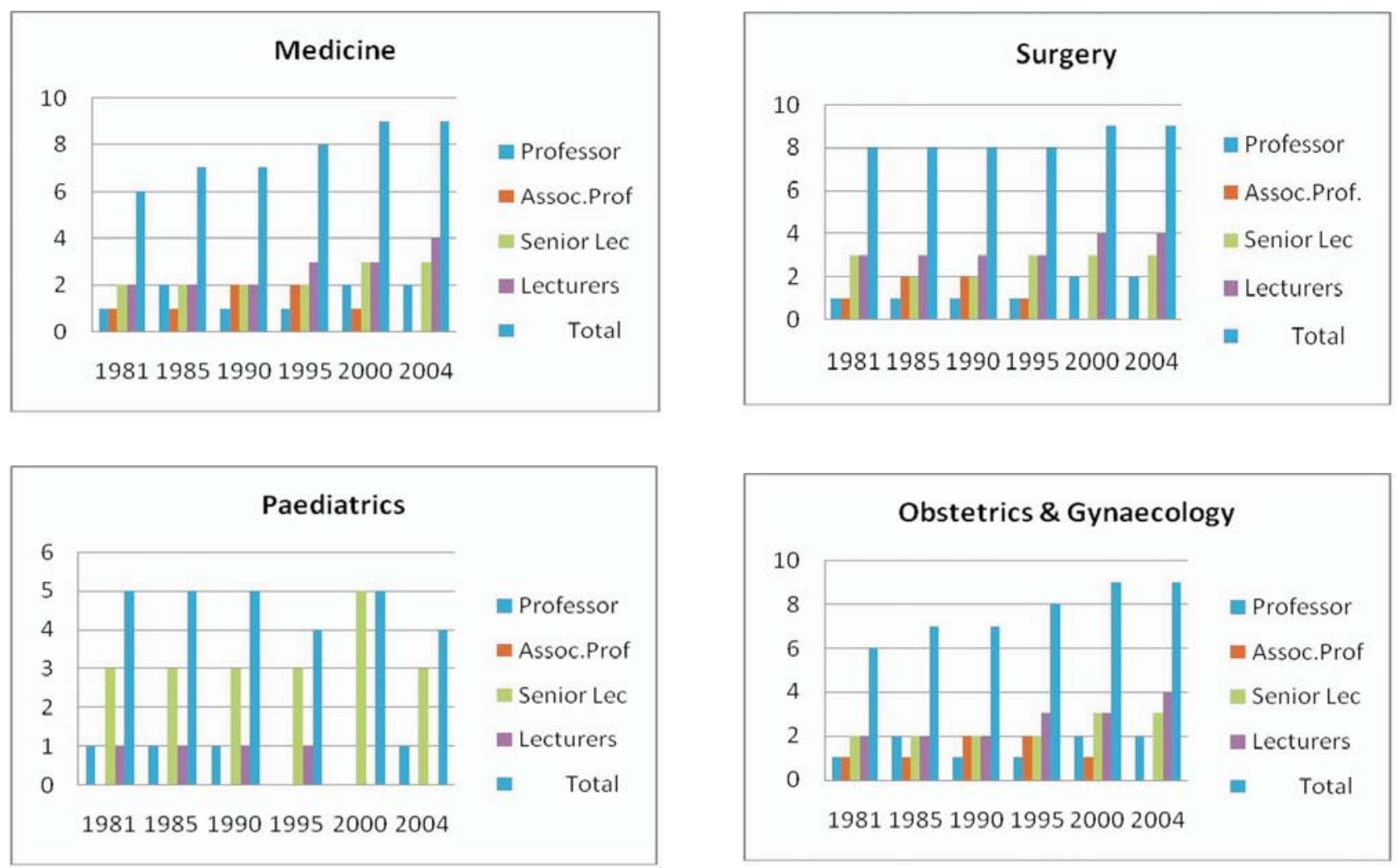

Figure 1: Staff profile in each department from 1981 to 2004.
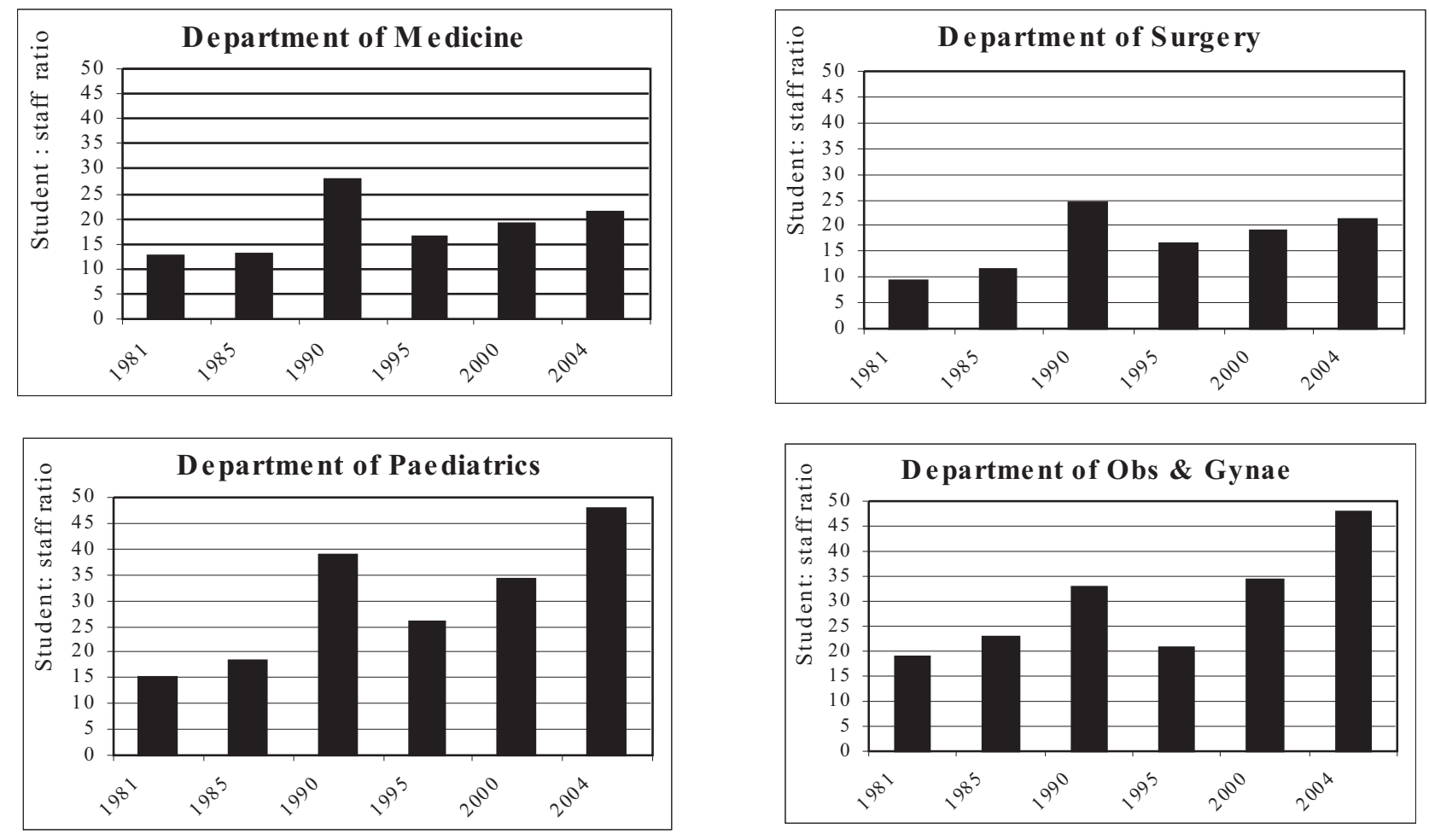

Figure 2: Student : Staff ratio from 1981 to 2004. 

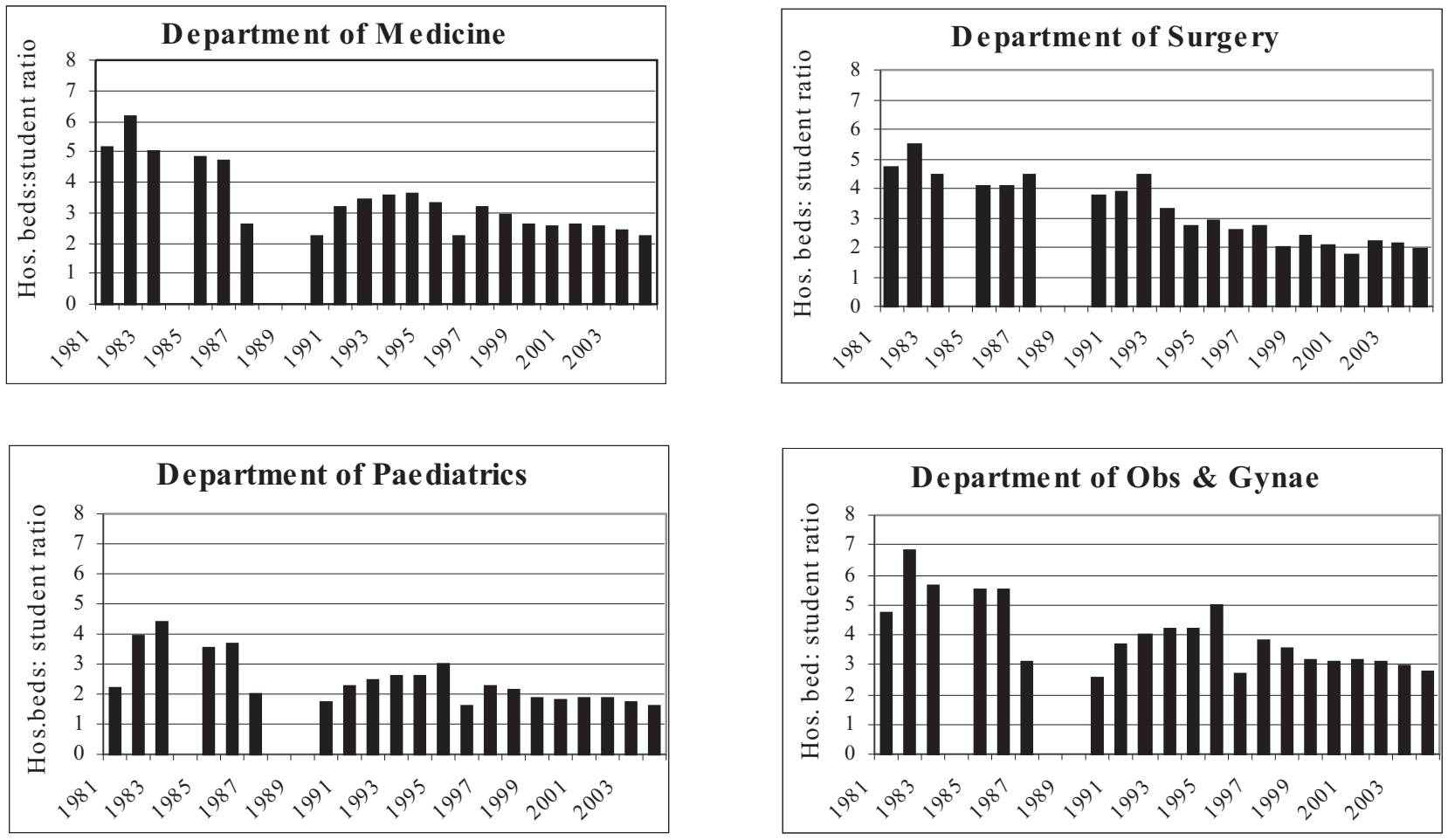

Figure 3: Hospital beds : Student ratio from 1981 to 2004.

Table 2: Recurrent expenditure per student per annum from 1994 to 2004. (Adjusted for Colombo Consumer Price Index)

\begin{tabular}{lccccccccc}
\hline Department & $\begin{array}{c}\text { Number of } \\
\text { students }\end{array}$ & $\begin{array}{c}\text { Annual } \\
\text { expenditure per } \\
\text { department (Rs.) }\end{array}$ & $\begin{array}{c}\text { Annual expenditure per } \\
\text { student (Rs.) }\end{array}$ & $\begin{array}{c}\text { \% Change } \\
\text { 1994 to } \\
\mathbf{2 0 0 4}\end{array}$ \\
\hline & $\mathbf{1 9 9 4}$ & $\mathbf{2 0 0 4}$ & $\mathbf{1 9 9 4}$ & $\mathbf{2 0 0 4}$ & $\mathbf{1 9 9 4}$ & $\mathbf{2 0 0 4}$ & $\begin{array}{c}\mathbf{2 0 0 4} \\
\text { (Corrected) }\end{array}$ \\
Medicine & 138 & 192 & 2499128 & 5544987 & 18109 & 28880 & 12142 & $(-32.97 \%)$ \\
Surgery & 138 & 192 & 1809783 & 4097294 & 13114 & 21340 & 8972 & $(-31.58 \%)$ \\
Paediatrics & 138 & 192 & 1592870 & 4270918 & 11542 & 22244 & 9352 & $(-18.97 \%)$ \\
$\begin{array}{l}\text { Obstetrics \& } \\
\text { Gynaecology }\end{array}$ & 138 & 192 & 1124653 & 2501453 & 8149 & 13028 & 5477 & $(-32.78 \%)$ \\
\hline
\end{tabular}



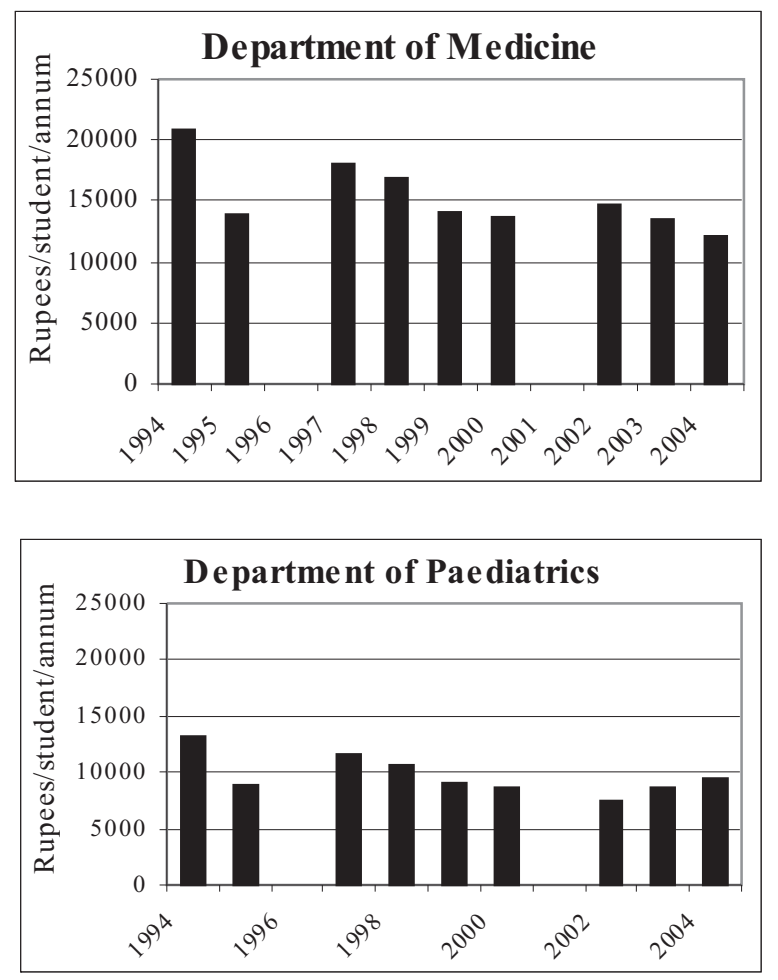
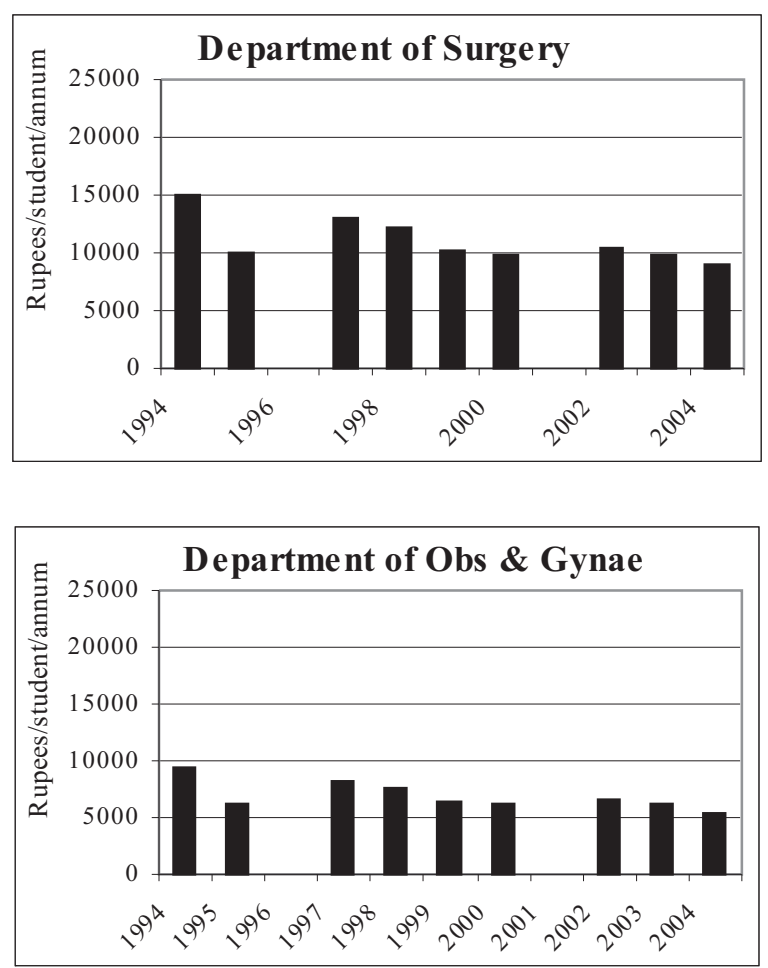

Figure 4: Recurrent expenditure in Rupees per student per annum from 1994 to 2004 (Adjusted for Colombo Consumer Price Index.)

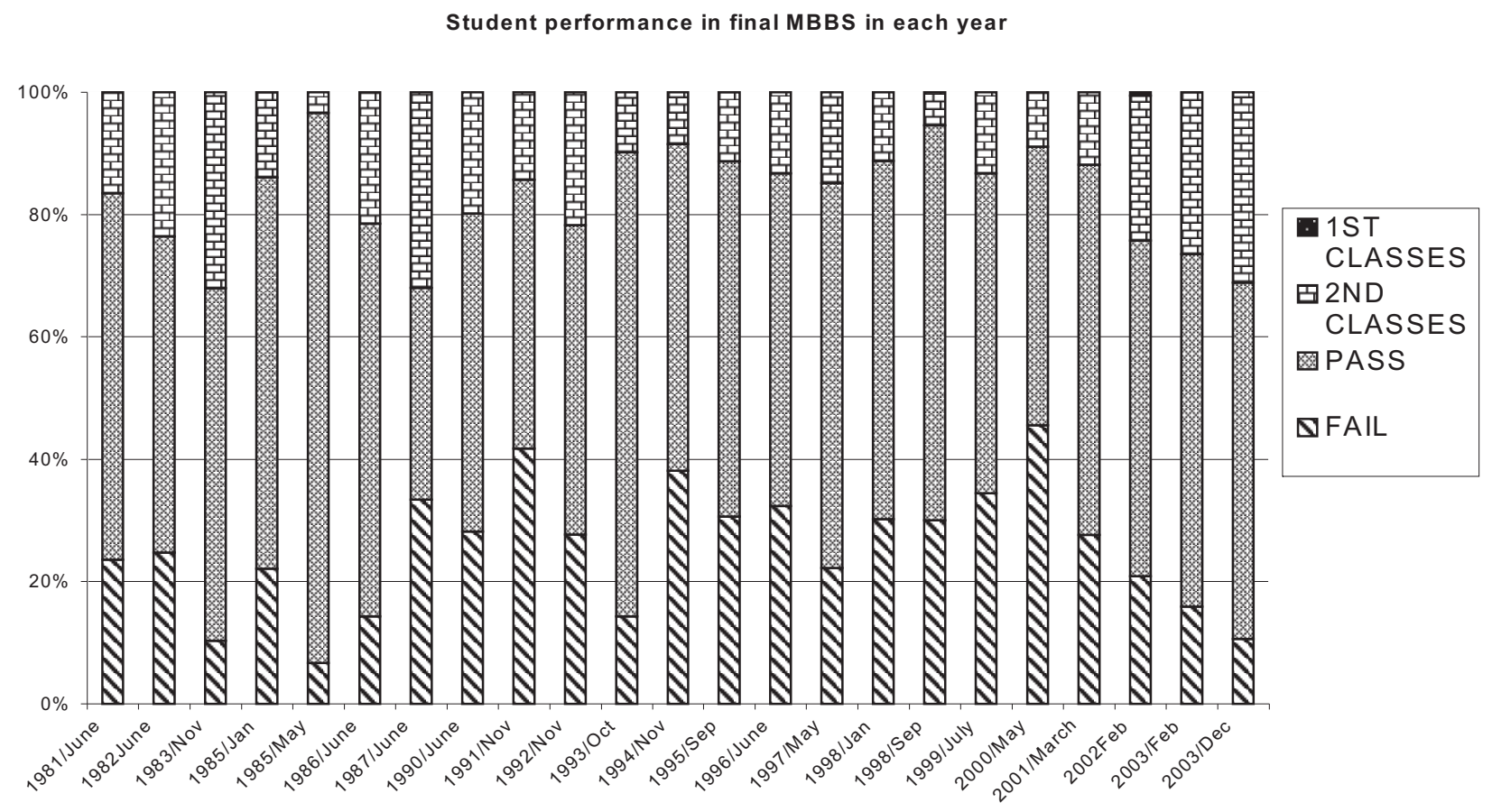

Figure 5: Student performances in Final MBBS from 1981 to 2004 


\section{Discussion}

In 1999, the South East Asian Regional Office of WHO (SEARO) has recognized the need for quality assurance of undergraduate medical education in the region. As a result, a national consultative meeting was held in Colombo in December 1999 and a recommendation was made to appoint an accreditation committee to decide on the minimum standards and criteria appropriate to Sri Lanka, while taking into consideration the world standards and the recommendations of the World Federation for Medical Education (WFME) (8). The standards of WFME were since upgraded and structured on 9 broad components (9), namely, (i) Mission and objectives (ii) Educational programme (iii) Assessment of students (iv) Students (v) Academic staff / Faculty (vi) Educational resources (vii) Programme evaluation (viii) Governance and Administration and (ix) Continuous renewal (9). The students, academic staffs of the faculty and educational resources account for one third of the 9 broad components. Our study discusses some important sub areas of these three broad components in relation to the Professorial Clinical Units at the Peradeniya medical school. In this context, our study reveals that, the resources made available for undergraduate medical education have not been revised adequately to reach the requirements of the increasing student numbers. We observed a steady increase in student: staff ratio due to the inadequate upgrade of full time academic staff positions along with the increased student intake. The worse ratios noted in 1990 reflected in addition the 'brain drain' that occurred because of the 1988-89 political unrest in the country. Although one may argue that the role of visiting staff has not been taken into account, the University Grants Commission of Sri Lanka has recommended an academic staff: student ratio of $1: 7$ for medical schools in keeping with the requirements of the WFME. Therefore, for an average batch of 192 students, there should be 28 academics staff positions serving the final year. These recommendations have accounted for staffs who may be on leave and hence is not a confounding factor for our analysis and interpretation. Thus, in proportionality, the academic staffing falls far short of the recommendation by at least $25 \%$ even at the best of times. The full time academic staff members have an important role in teaching medical students and organizing undergraduate programmes of education (especially small group teaching needed to inculcate clinical skills, attitudes and values of the profession) including assessments. Therefore, inadequate academic staff numbers would incur adverse effects upon the quality assurance of medical education. The damage done may not be obvious as the assessments are mainly designed to assess technical competence of the students. Furthermore, the implications of this upon the research output and other academically oriented activities of the faculty would be far greater as all staffs would be maximally stretched to fulfill the undergraduate needs. This is reflected by the relatively unchanged student performance in the final year examinations over the years despite staff shortages but reduced research output making a grim impact on the world ranking status of the university (World Rank Colombo 2185, Peradeniya 3005) (10). Furthermore, it should be emphasized that, many academic members of the clinical professorial units undertake a significant service workload in hospitals that cannot be postponed or ignored. This includes the services rendered for an added unaccounted number of 'floor patients' who are not allocated to beds. The nonexpansion of the hospital bed strength along with the increasing student numbers in parallel was reflected by the stepwise reduction in the hospital beds: student ratio since 1981. This has contributed to overcrowding of the professorial units by students resulting in a poor learning environment. The Ministry of Health led administration at the Teaching hospital Peradeniya sadly has not paid adequate attention to rectify these escalating deficiencies along with the increasing number of medical undergraduates. On the contrary, during this study period, the number of designated student learning rooms in hospital was reduced from 4 to 2 due to hospital authority acquisition of those to cater for the service needs. The inadequately upgraded physical facilities for clinical teaching could be attributed to poor communication and understanding between the two authorities i.e. the Ministry of Health and the Ministry of Higher Education and reduced budgetary allocations. The WFME, recommends that the medical schools must ensure adequate clinical experience and the necessary resources, including sufficient patients and clinical training facilities to achieve the basic standards. Thus, it is essential that the resources made available for clinical teaching be linked to student numbers to ensure a minimum 
standard for clinical teaching in hospital and to safeguard the quality of undergraduate medical education. This is because, in Sri Lanka, the hospitals form the main clinical teaching environment for all state run medical schools.

Regrettably, our data show that despite the increased costs of medical education and student intake, the allocation of funds have virtually remained static or have reduced proportionately per student in 3 of the 4 clinical departments. WFME considers that, physical facilities and capacity for clinical teaching play a major role in determining the quality of educational programs and outcome measurements (11). Therefore, this deteriorating level of facilities and funding may contribute to the deterioration of standards in undergraduate medical education. Unfortunately, the faculties are not permitted to compensate for the financial deficits through the recruitment of fee levying students and hence there is no sustainable recue other than the occasional relief received through ad hoc additional funds obtained via donor agencies.

Our data reflects the trends at the Faculty of Medicine, Peradeniya, that would be equally applicable to other seven medical schools in the country. This is because, the government allocated recurrent funding for medical schools is based on a national formula applied by the University Grants Commission. Since all medical faculties are state governed, the situation is likely to be similar in other faculties too.

\section{Conclusion}

Our study highlights a declining trend in academic staffing, government funding and hospital facilities available for undergraduate final year clinical medical education at the Faculty of Medicine, Peradeniya, over the period of study from 1981 2004. We consider that benchmarking a basic standard for academic staffing, annual recurrent expenditure and the number of hospital beds available per medical student would ensure a stable learning environment for the undergraduates in Sri Lanka medical schools in keeping with the expected quality and standards of World Federation for Medical Education.

\section{Acknowledgements}

We are grateful to all institutions and faculty staff for providing material and information for this study. We thank Mr. Mahes Salgado for his contribution in the preparation of the manuscript.

\section{References}

1. De Silva NR, Samarasinghe HHR. Quality in medical education. Ceylon Medical Journal.2000; 45: 55-57.

2. Department of Census and Statistics- Sri Lanka, Annual Report; 2004: Universities and Education from http://www.statistics.gov.lk/education/school_university. pdf

3. Wikipedia. The free encyclopedia. http://en.wikipedia.org/ wiki/Medical_school\#Sri_Lanka

4. Elam CL, Scott KL, Gilbert LA, Hartmann BA. A comparison of applicant and matriculant trends, and rising costs of medical education in United States medical schools and at the university of Kentucky College of Medicine .Journal of the Kentucky Medical Association. 2003; 101: 201-7.

5. Morrison G. The cost of medical education. The New England Journal of Medicine. 2005; 352: 117-9

6. Seifer SD. Recent and emerging trends in undergraduate medical education-curricular responses to a rapidly changing health care system. West j Med 1998; 168: 40041.

7. Central Bank Annual Report-1998 \& 2004, Statistical Appendix, Prices and wages; 39-40 from http://www.lanka. net/centralbank/Stat.\%20Appendix-04.pdf

8. World Federation for Medical Education. Basic Medical Education WFME Global Standards Quality Improvement from http://www.sund.ku.dk/wfme/Activities/ Translations/Documents/WFME/Standard.pdf

9. World Federation for Medical Education: Basic Medical Education. WFME global standards for quality improvement: WFME office: University of Copenhagen. December 2003 http://www3.sund.ku.dk/Activities/ WFME $\% 20$ Standard $\% 20$ Documents $\% 20$ and $\% 20$ translations/WFME\%20Standard.pdf

10. Ranking web: Universities by country http://www. webometrics.info/rank_by_country.asp? country $=1 \mathrm{k}$

11. World Federation for Medical Education. International Standards in Medical Education: assessment accreditation of medical schools' educational programmes. A WFME position paper. Medical Education 1998; 32: 549-58. 